\title{
Predicting the Length of the 2003 U.S.-Iraq War
}

\author{
D. Scott BennetT
}

The Pennsylvania State University

Allan G. Stam

Department of Government

\begin{abstract}
On April 1, 2003, we published a set of contingent predictions about the likely length of the U.S.-Iraq war that began on March 19, 2003. The predictions were made by applying the statistical model of war duration developed in Bennett and Stam (1996). In this article, we assess the accuracy of our (then) forecast, and then present new predictions from the model about the expected length of a punishment/guerrilla war in Iraq, a hypothetical war between the U.S. and Syria, and a hypothetical war between the U.S. and North Korea. Our forecast of the duration of a punishment/guerrilla war in Iraq is 83 months. Our earlier forecast and the new predictions suggest that our model of war duration is a useful tool for thinking about the politics of war duration as well as war initiation.
\end{abstract}

The ground campaign of the 2003 war between the United States and Iraq was notable for its speed and the rapid collapse of Iraqi conventional military resistance. By the summer of 2005, ongoing fighting among multiple insurgencies in Iraq remained notable both for the insurgents' existence in the context of the Bush administration's pre-war optimistic forecast of widespread support for a new regime in Iraq, as well for the steady pace of increasingly effective attacks against U.S. and the new Iraqi government's forces.

The conventional ground war began in March 2003 with Operation Shock and Awe, a massive bombardment of hundreds of military sites in Baghdad and other locations in Iraq. Journalists embedded with the rapidly advancing ground forces recorded the collapse of the Iraqi military for the world to watch on the evening news. Except for isolated "pockets of resistance," the majority of Iraqi forces were quickly defeated, and many Iraqis seemed to welcome the American and British forces with open arms. Within weeks of the opening salvos, statues of Iraqi President Saddam Hussein toppled across Iraq in one newscast after another. With relatively few coalition Military casualties (173 coalition troops) ${ }^{1}$, on April 30, 2003

Author's note: Data and spreadsheets to accompany the original research report are available online at http:// polisci.la.psu.edu/faculty/bennett/warduration.html. Research assistance was provided by Kyle Joyce and Faten Ghosn, The Pennsylvania State University.

${ }^{1}$ But larger numbers of Iraqi casualities, including an estimated 7,300 civilians. The number of civilian casualties is controversial. We cite figures from www.iraqbodycount.net, an independent organization cataloging casualties mentioned in public news reports. According to their figures, civilian casualties from the post-war occupation exceed 20,000 as of October 2005. Roberts et al. (2004), estimated that over 100,000 civilians were dead by the middle of 2004 . 
just 41 days after the beginning of the war, U.S. President George W. Bush declared an end to major combat operations between the coalition forces and the Iraqi military. President Bush claimed that the war was over, and that the U.S.-led coalition had won. While subsequent events during the occupation of Iraq have demonstrated that substantial resistance to U.S. influence and the new Iraqi government remains, it is undeniable that the prototypical massive, conventional, organized interstate war had ended by late April.

By historical standards, this six-week conventional U.S.-Iraq war was quite short. The median duration of all interstate wars since 1816 is approximately five months, while the mean duration is well over a year. ${ }^{2}$ In the first days of the war, however, it was not so clear whether the U.S. technological might would prevail quickly. In fact, in the early days of the war, the media presentation of the war was a roller coaster, shifting in rapid succession from an upbeat assessment of the prospects for a quick U.S. victory to a fear that the war would be long and difficult. On the seventh day of the war (March 26, 2003), the New York Times went so far as to suggest that the U.S. was already "bogged down" in its fighting in Iraq. On that day, the Times published a full-page timeline of the first seven days of the war, labeling each day with its assessment of the "flavor" of this part of the conflict. U.S. progress was assessed as shifting from "Early Success" on day 3 of the war, to a "Day of Setbacks" on day 5, to "Bogged Down" on Day 7 (New York Times 2003). Knowing the median length of war historically, it was ridiculous to think that the war should be nearing a conclusion after 7 days of fighting, or that 7 days should determine the outcome or likely duration of the conflict. But the assessment was more understandable in a context of a news world requiring rapid assessments; with a U.S. public used to rapid victory, a slowdown in progress and the first U.S. military fatalities led to a rapid shift toward a dire assessment of U.S. prospects in the war.

In the initial phase of the war, neither the Pentagon nor the White House provided any data or forecasts that would help either reporters or analysts understand how long the war was likely to last. ${ }^{3}$ It seems implausible that the Pentagon did not have estimates of the war's likely initial duration, outcome, and cost; planning for war and providing estimates of what would happen and what resources would be needed to win are part of what the military does, after all. We suspect that leaders had a range of best-case to worst-case estimates as the Pentagon wargamed out the conflict under a variety of assumptions. ${ }^{4}$ But the Pentagon did not make public pronouncements about the likelihood or speed of victory, except vaguely, just as since the Vietnam war it no longer publicly estimates enemy military (or civilian) casualties. No independent assessment of the war's likely outcome and duration was available either. So the public and scholars were left with little in the way of alternative perspectives to the "bogged down" sentiment one week into the war.

A similar situation exists in the fall of 2005 in terms of understanding how long the war in Iraq will continue in its new form. After the initial victory in conventional battle against the Iraqi military, the summer of 2003 witnessed the beginnings of

\footnotetext{
${ }^{2}$ In measuring the duration of wars, we generally follow Small and Singer's (1982:65-66) procedures, which identify the starting and ending dates of war by a combination of when actual sustained fighting began and ended, along with information about formal declarations of war and signed armistices. Where there is a substantial difference between actual behavior (fighting) and the legal dates of declarations/treaties, priority is given to when actual combat occurred. We discuss how we identify the end of the first phase of the Iraq war in detail below.

${ }^{3}$ Secretary of Defense Donald Rumsfeld stated on National Public Radio on November 14, 2002 "I can't say if the use of force would last five days or five weeks or five months, but it certainly isn't going to last any longer than that." This was well before the war. This appears to be his most definitive public statement on the matter, and once the war began, no estimates were given. Some estimates appeared about monetary costs (e.g., OMB estimates, and long-term estimates in the New York Times Op-Ed by Gordon Adams and Steve Kosiak on February 16, 2003), and Cioffi-Revilla (1991) presented estimates concerning the 1990 U.N-Iraq war. However, we know of no other duration and outcome estimates presented in the runup to the 2003 war.

${ }^{4}$ Personal conversation with Col. Bruce A. Lindblom, Director, National Strategic Gaming Center, National Defense University, Fort McNair, Washington, DC.
} 
the now-substantial insurgency against U.S. and newly formed Iraqi military and police forces. In fact, given political goals of stabilization and democratic transition, it has become unclear now (2005) whether or how U.S. technology and limited forces will prevail against the post-conventional-war insurgency. But the public and scholars are again left with no estimates as to whether the war against insurgents in Iraq can be won, or at what cost, or how long it will take. Although we know that there have been a variety of reports circulated within the administration concerning the strength of the Iraqi resistance, and although U.S. Secretary of Defense Donald Rumsfeld has acknowledged that insurgencies typically continue for 5-12 years (Knowlton 2005), we do not know whether there has been an internal bottom-line prediction as to costs of the war (in time, lives, or money), or what that prediction is.

In assessing the confusion over the war's likely length in March 2003 (and today), we applied a previously published statistical model of war duration (Bennett and Stam 1996) to the U.S.-Iraq war to make an informed prediction of the war's duration. This model estimated the effect of a variety of factors on the duration of interstate wars between 1816 and $1985 .{ }^{5}$ The statistical model was designed as a theoretical model rather than specifically for forecasting. The major goal of our 1996 article was to assess alternative causal claims about the effects of several variables on war duration, and to assess the presence of duration dependence in interstate war. If we had wanted to maximize forecasting accuracy for future wars, we would have constructed the model differently, with a larger number of interactive factors and greater attention to trends and changes over time. However, even though the model was not designed from the ground up as a forecasting model, we could still take the coefficient estimates from it and make a prediction about the duration of the ongoing war with Iraq. In late March 2003, we used the model to make a series of contingent predictions of the likely duration of the U.S. war with Iraq. Not being as worried as the Pentagon about being wrong in our pronouncements, we announced and published the results of these predictions on the web in the form of a research report on April 1, 2003 (the original report is still available at http://polisci.la.psu.edu/faculty/bennett/warduration.html). We revisit those predictions here, first reviewing our estimates of the U.S.-Iraq war's likely duration, and then presenting three extensions of our model.

The rest of this article proceeds as follows: first, we include the verbatim text of the original research report published on April 1, 2003. Those who wish to check can verify that this is the original text; we believe it is important to present this in its original form to allow an honest assessment of it. Second, we assess how well we did in our predictions. Third, we present new estimates of three other interesting, and contrasting, possible war scenarios. We examine possible wars between the U.S. and Syria, between the U.S. and North Korea, and between the U.S. and Iraq but under the current conditions of an Iraqi guerrilla/punishment war against the U.S. We believe that contrasting our estimates about the duration of the U.S.-Iraq war to these other situations can shed light on other policy decisions and even international reaction to the U.S. war with Iraq.

Note that in the research report, we provided a brief discussion of several technical issues concerning coding and methodology that are addressed fully in Bennett and Stam (1996). We refer interested readers to that article for further discussion of the original model and statistical methodology.

\footnotetext{
${ }^{5}$ Since we published our model in 1996, we (and others) have re-analyzed our data, making several different extensions. For instance, Goemans (2000) extends the model by hypothesizing that mixed regimes fighting a losing war will significantly extend wars' duration. Slantchev (2004) extends the model by focusing on war termination as an endogenous process, with information exchanged over the course of a war serving to reduce uncertainty in the likely outcome. We have conducted reanalysis focusing primarily on the statistical model, and have verified that the results hold up when using a Cox rather than a Weibull duration model, when we account for nonproportional hazards, and when we extend the data to 1992. The main results of the model still hold up in the face of these changes.
} 


\section{Part 1: April 1, 2003 Research Report Text \\ Overview}

In 1996, we analyzed the duration of interstate wars between 1816-1985 (Bennett and Stam 1996). The primary focus of our analysis lay in determining how several theoretical factors have influenced the duration of war, and whether their influence matches our theoretical understanding of war. The model may also be used to forecast the duration of other out-of-sample wars (in the 1996 article we post-dicted the length of the 1990-1991 Gulf War, which was not in our sample). In this report, we use the model presented in Bennett and Stam (1996) to predict the likely duration of the $\mathbf{2 0 0 3}$ war between the United States and Iraq.

Our model includes military, political, demographic, industrial, and geographic factors. It is not based on the type of intense wargaming that has been conducted by the U.S. military, but rather is based on a statistical model that quantifies the effect of multiple factors on the duration of wars since 1816. By focusing on the factors that have affected war duration historically, and comparing the duration of many wars over a long time period, we can make projections about current and future conflict. Since 1816, the median war has lasted approximately 5 months, with the mean duration at approximately 17 months. Our model can do better than just predicting the mean or median however, and ultimately, we present our estimates of the likely duration of the 2003 U.S.-Iraq war under four scenarios. Our best estimate of the likely duration of the war (given the evolution of the war thus far, and assuming that the United States is able to maintain its maneuver-based strategy) is approximately $2 \frac{1}{2}$ months. If the U.S. is forced to turn to a pure attrition-based strategy in which it is forced to defeat most or all Iraqi units through direct combat, our estimate of the war's possible duration stretches to nearly a year.

\section{The 1996 Model}

Bennett and Stam (1996) used a statistical model applied to a database of 78 wars between 1816 and 1985 to determine what factors influence war duration, and how. Specifically, a hazard model with a Weibull formulation was employed on a data set constructed with time-varying covariates, with each observation in the data set consisting of a war-year (hazard models are also referred to as event history models, survival models, or duration models in various disciplines). ${ }^{6}$ After adequate control variables were introduced, duration dependence was found to be nearly eliminated in the data.

\footnotetext{
${ }^{6}$ [Note added 2005] General presentations of hazard models include Allison (1984) and Lancaster (1990). Presentations of this type of model as particularly relevant in political science include Box-Steffensmeier and Jones (1997, 2004) and Bennett (1999). Generally speaking, a hazard model is a regression-like model appropriate for analyzing the duration of events (such as wars). Hazard models focus on the hazard rate, which in our case represents the instantaneous rate at which a war terminates at time $t$, given that it has survived until time $t$. Although technically not a probability, it is intuitive to think of the hazard rate as roughly analogous to the conditional probability of a war terminating after some duration $t$. The lower the hazard rate (the lower the probability of termination at any point), the longer the war is expected to last. The hazard rate is modeled as a function of a set of variables, including time, and so if we believe that some factor is likely to make wars shorter or longer, we can include that factor as a parameter in our model. The hazard need not be constant over time, and one important use of hazard models is in identifying the "duration dependence" of a process, that is, whether the process tends to become institutionalized (and stretch out) as it becomes longer, or if it is "self-terminating" and is expected to end more quickly the longer it continues. Hazard model estimation produces a set of coefficients and standard errors which can be interpreted much like a regression or logit estimation in terms of assessing the so-called "statistical significance" of variables. While direct interpretation of the final estimated $\beta$ coefficients is difficult due to hazard rate formulas and the presence of non-linearity, we can also use the coefficients to produce marginal effects (e.g. to estimate the effect of military strategy or force balances on the duration of a war). We can also use the coefficients in the appropriate expected value formulas to predicted outcome durations for any circumstance we can specify with our variables. In particular, the expected survival time for any given case (set of values $x_{i}$ ) given the Weibull distribution, as noted in the appendix to the research report, is $E\left[t \mid x_{i}\right]=\exp \left(\beta^{\prime} x_{i}\right) \times \Gamma(1 / \rho+1)$, where $\Gamma$ is the gamma distribution, and $\rho$ is the estimated duration dependence parameter. At the simplest level, positive coefficients in $\beta$ predict longer duration and negative coefficients predict shorter durations.
} 
The data set analyzed in the statistical model included all interstate wars fought between 1816 and 1985 for which adequate statistical data were available. Wars were identified by the Correlates of War Project according to standard criteria; independent variable data in the project came from the Correlates of War Project data sets (e.g. Small and Singer 1982; http://cow2.la.psu.edu), the Polity data project (e.g. Jaggers and Gurr 1995; http://www.cidcm.umd.edu/inscr/polity/index.htm), and research by Bennett and Stam (e.g. Stam 1996). The Correlates of War project is a $40+$ year long project originally started at the University of Michigan (now continuing at the Pennsylvania State University), which is designed to categorize and systematically collect statistical data relevant to international conflict over a long timespan. Of particular importance to predicting war duration, the project has catalogued the national capabilities of every country in the international system since 1816 (including military and industrial capabilities, and demographic characteristics), has identified and measured critical aspects of every international war since 1816, and has identified each militarized dispute short of war occurring between countries since 1816 .

Factors (independent variables) in the statistical model included:

- the military strategy of the two sides fighting the war;

- the terrain on which the war was fought;

- how well the terrain suited the strategy employed by each side;

- the balance of military capabilities between the two sides;

- the total reserves of the two sides in terms of total military personnel, and total national population;

- the difference in quality and equipment of the militaries involved;

- the presence or absence of major military surprise in the war;

- the salience of the issues at stake in the war;

- the political characteristics of the regimes engaged in the war, in terms of internal repression and democracy;

- the background of the contest in terms of the presence or absence of prior disputes before the war;

- the number of states involved on each side of the war.

Expectations about how these factors (variables) were expected to influence war duration were developed and fully explained in the original article. For instance, we expected that the more imbalanced any military contest (in terms of military capabilities), the shorter the war would be. Similarly, we expected that the more imbalanced the training and equipment between the two sides, the shorter the war would be. By contrast, we expected that the greater the reserves of the two sides in military personnel and population, the longer the war would be. The statistical model ultimately included 17 variables, each of which had some expectation attached to it. More importantly for our purpose here, however, statistical analysis of the set of wars over the past two centuries revealed the magnitude of effect of each variable on war duration, allowing us to make numeric forecasts about any situation by applying our quantitative coefficient estimates to that situation.

Two critical factors deserve special highlighting here. First, we categorized military strategy into three broad types, maneuver or movement strategies, attrition strategies, and punishment strategies. Maneuver strategies (often referred to as "blitzkrieg" strategies) are those where states focus on the use of speed and mobility to cut supply and communication lines, isolate enemy units, and disarm the opponent by disrupting their ability to effectively organize their forces. Under this strategy, the enemy is defeated without necessarily destroying each enemy force. By contrast, attrition strategies seek to destroy or capture opposing forces through direct combat, without necessarily using mobility to achieve this. Typically an attrition strategy seeks large confrontations with the enemy, and seeks actual physical destruction of enemy forces. Punishment strategies attempt to inflict such high human and material costs (ultimately influencing political calculations) on an opponent that they cease an 
attack or surrender even though their military forces may not actually be defeated in battle. Punishment counts on being able to break the resolve of the enemy, and is often not a purely counter-force (counter-military) strategy. In any war, we identify the primary strategy of both the offensive and defensive side; nine strategy combinations are possible. Wars where one or both sides employ movement strategies have been the quickest historically, while wars where one or both sides employ punishment have been the longest.

Second, we code terrain on a 0 to 1 scale, where " 0 " marks open or rolling terrain and " 1 " marks impassable terrain. Dense terrain (heavy woods, jungles, swamps, mountains, or some cities) hinders the movement of military forces, and allows military forces to hide quite easily. ${ }^{7}$ Such terrain makes ambushes possible, while also allowing forces suffering damage to move out of the battle and hide. Wars fought in dense terrain will last longer, while wars fought on flat, more open terrain will be shorter, as forces can move quickly and fight decisively with little time lost in finding the opponent.

Terrain and strategy choice also interact, as some strategies work better in particular terrain than others. For example, rough terrain is better suited to use of a punishment strategy than a maneuver strategy, since rugged terrain hinders rapid movement and decisive battle but allows forces to inflict costs upon their opponent with relative impunity. On the other hand, open terrain is better suited for the use of a maneuver strategy, as forces can spot enemy forces and move quickly to cut supply and communication lines.

\section{Extensions}

The 1996 model included wars begun between 1816 and 1985 (data on key independent variables were not yet available for wars after 1990). Before forecasting the duration of the $\mathbf{2 0 0 3}$ war between the United States and Iraq, we re-estimated the model after adding data on wars during the 1985 to 1992 period. In particular, this period included two military contests of great relevance to a model predicting current war duration, the Iraqi invasion of Kuwait in 1990, and the subsequent invasion of Iraq (and corresponding expulsion of Iraq from Kuwait) by the United States in 1991. It was important to add these wars because the 1991 Gulf War in particular was seen by many as surprisingly quick, and perhaps as a harbinger of a new type of war. In fact, the 1991 Gulf War fits into the model very well historically as a quick war; it was a war with limited aims, with clear military and technological superiority of one side over the other, and with a maneuver strategy on the ground executed well by United States military forces. But as additional data to be considered in comparison to other wars, the speed and characteristics of that war are particularly important.

Our re-analysis actually adds two new military conflicts corresponding to two distinct phases of the 1990-1991 Gulf War, the Iraqi invasion of Kuwait in 1990, and the U.S. war on Iraq in 1991. It is important to include these in the analysis as separate military contests, in keeping with our prior split of major wars such as WWII, because the military aspects of the first invasion were clearly well settled before the second could be planned, let alone launched.

The statistical estimates of the resulting model after adding these two wars look generally similar to the estimates from the 1996 model, certainly at the level of hypothesis testing as conducted in Bennett and Stam (1996). The values of some parameters did change, particularly the estimated effects of terrain and the terrain/ strategy interaction. It is particularly important to use the new values for forecasting

\footnotetext{
${ }^{7}$ In practice, the densest terrain type we observe has a scaled value of 0.75 . We can code terrain for wars fought over multiple terrain types by using a weighted average. In practice, many wars with a mix of terrain had terrain values between 0.4 and 0.5 , with the European theater of WWII (with a mix of dense woods, open hills and fields, and cities) having a value of 0.45 .
} 
purposes in the current war. The new statistical results are contained in the Appendix below, and in the forecasting spreadsheet. The data set, command file to reproduce the analysis, and forecasting spreadsheet are available on our website for this report.

\section{Assumptions and Values}

In this forecast, we assume a 3-state war involving the United States, Britain, and Iraq. The United States and Britain are the major "coalition" partners at this juncture, with over 250,000 and 45,000 troops in the region respectively engaged in the war. Australian forces numbering approximately 1000, and Polish forces numbering approximately 200, are not adequate to substantially shift the balance of forces or the basis of political discussion. On the Iraqi side, although there have been reports of shipments of equipment to Iraq from Russia and Syria, no other state has military forces actively engaged in the war, and shipments appear quite small relative to total forces involved.

In the scenarios presented, we vary two critical components of the model for forecasting purposes, namely strategy and terrain. Other aspects of the model-military capabilities, population, government characteristics, achievement of strategic surprise (in this case, the lack thereof) - are fixed in the time frame of the model. But depending upon the evolution of the war over the next weeks, the strategy employed by the United States may change, along with the terrain in which it must fight. We assume in alternative scenarios that the United States will be able to maintain its maneuver strategy against an Iraqi attrition-style defense, or will be forced to shift to a more purely attrition-based offensive seeking to destroy Iraqi forces directly. We also assume in alternative scenarios that the United States will maintain its ability to remain in and attack on relatively open terrain, or will begin to engage in battle in cities as well as open terrain. We thus vary strategy between OMDA (offense-maneuver, defenseattrition) and OADA (offense-attrition, defense-attrition), and vary terrain between 0 (open, rolling) and 0.45 (mix of open and dense terrain).

\section{Summary of Forecasts}

We make a set of contingent predictions about the 2003 war.

\begin{tabular}{lllll}
\hline Scenario: & 1. & 2. & 3. & 4. \\
& U.S. maneuver & U.S. maneuver & U.S. attrition & U.S. attrition \\
& Iraq attrition & Iraq attrition & Iraq attrition & Iraq attrition \\
& Open terrain & Mixed terrain & Open terrain & Mixed terrain \\
Expected duration (months): & 0.88 & 2.50 & 10.63 & 12.27 \\
\hline
\end{tabular}

If the conditions of scenario 1 hold, a war in which the U.S. continues to rely on maneuver while being able to remain in open terrain, the war would be expected to last about 1 month. As of this date, however, it appears that this situation may not hold. The U.S. has been forced to return units from the front to guard its own supply lines, not all bypassed Iraqi units have collapsed, and the United States and allies have begun entering cities, suburbs, and villages to search for Iraqi forces. It appears that we may soon be past this scenario.

In the second scenario, we assume that the U.S. is able to maintain and use its airpower and highly mechanized forces in movements to fight Iraqis on U.S. terms, but in a mix of open and city terrain. As of this report date, this is what we currently see - the U.S. is using its technology, and tactical and strategic mobility, to attack Iraqi forces by and-large when and how it chooses. U.S. ground forces are remaining largely in the open looking for opportunities, but are increasingly engaged in searches of villages and battles within towns such as Nasiriyah, while not committing to fullscale city warfare. We believe this is currently the most likely scenario for the war in the near future. If the U.S. must engage in battle in both open and dense terrain, the model forecasts that the war is likely to last $2 \frac{1}{2}$ months. By historical standards (with over half of all wars since 1816 lasting more than 5 months), this would still be a short war. 
In scenario 3, we assume that the reliance on movement, airpower, and disarming the Iraqi army does not work. If isolated Iraqi units do not collapse, have large weapons caches accessible without supply lines, and continue to fight around the country without central orders, then the U.S. might be forced to turn to a classic attrition strategy. In scenario 3 , the assumption is that the U.S. military will need to largely destroy the Iraqi military unit by unit, but will manage to do so while staying out of cities. In this case, the expected length of a war jumps to $10 \frac{1}{2}$ months.

In scenario 4, we begin with the scenario 3 assumptions that the reliance on movement, airpower, and disarming the Iraqi army does not work, and that the U.S. will turn to an attrition strategy. However, we also assume that the U.S. military will be required to fight in major cities as well as in more open terrain. This further lengthens the expected duration of war to approximately a full year.

An attrition war that must be fought in the cities of Iraq brings the most uncertainty in duration of all the scenarios. The U.S. has an unprecedented advantage in technology and training over the Iraqi army that could lead to a further change (shortening) of war duration in any of the scenarios. On the other hand, the U.S. military has not fought to take a major city in the recent past; modern urban warfare may prove more difficult than anticipated. ${ }^{8}$ This may be offset if Baghdad proves to not be the urban warfare nightmare envisioned in worst-case scenarios; some commentators have noted that the city has relatively low buildings and large open areas (at least near the political district). If this makes the difference, then even if the U.S. fights in Baghdad, military progress could be faster than expected.

Finally, given United States objectives, it is important to note that the war could end at any time if the current top leadership of Iraq is killed, deposed, or goes into exile. But to the extent that prediction is possible in the absence of such an unexpected event, the forecasts produced by the historical model suggest that the U.S. ability to execute its maneuver strategy in the face of opposition will make the largest difference in the likely duration of the war.

\section{Part 2: Assessment}

Given our April 2003 assessment of the various possible scenarios the U.S. might have pursued (entering cities vs. minimizing city engagement, and pausing to defeat sizable Iraqi forces vs. continuing to bypass enemy concentrations), our best guess about the likely duration of the U.S.-Iraq ground war was 2.5 months. How long was this part of the war? The question is more complicated than it appears because no cease-fire or peace agreement was ever signed between Iraqi military or political leaders and U.S. representatives. Rather, the Iraqi political and military leadership structures simply dissolved. Two possible lengths, 27 and 43 days, suggest themselves. On April 14, U.S. military forces occupied the Iraqi city of Tikrit, Saddam Hussein's hometown and the last major concentration of Iraqi troops. Fighting for Tikrit marked the last major battle between U.S. and Iraqi military forces until the subsequent insurgency escalated during the battles at Al-Fallujah in April and October 2004. Using the Tikrit battle to mark the end of the conventional war, the war lasted 27 days. A second possible date to use to mark the end of the war is May 1, the day George Bush declared the end of major combat operations in Iraq from the aircraft carrier U.S.S. Abraham Lincoln. Using May 1, the war's duration was 43 days. $^{9}$

\footnotetext{
8 [Note added 2005] In writing "recent" in the research report, we were referring to post-Vietnam war.

${ }^{9}$ Below, we discuss the continuing resistance to U.S. occupation and the insurgency that is continuing as of this writing, and recognize that more U.S. military personnel have been killed since the end of "major combat" than before. Many would assert that this means that the war is not in fact over. In terms of the major criteria we are interested in for an interstate war, however, organized combat between the regular armed forces of both sides ended in April 2003, and no organized military forces remain in continuing military contact with U.S. troops. Hence we assert that the war defined in terms of the referent historical criterion of regular conventional military combat ended
} 
How do 27 or 43 days compare with our estimates? Our estimated "best-case" scenario predicts that a duration of 0.88 months (27 days) equals the 27 -day duration marked by the Tikrit battle. In retrospect, the United States. managed to do exactly what was contingent in scenario 1, that is, largely avoiding city fighting and continuing to move rapidly through Iraqi forces rather than turning back to solidify its defeat of Iraqi forces in Iraq's south. Our "pick" between our four contingent scenarios was based on our reading of U.S. progress in the first two weeks of the war, namely that the U.S. was likely to have to enter and pacify major cities, facing the tougher terrain and battles therein. We could say that 43 days was not far off 2.5 months, and by historical standards it is not; however, it is generally clear that our scenarios somewhat overpredicted the duration of the initial, conventional war.

The range of contingent estimates reveals one weakness of using our model to forecast duration, namely the necessity of making contingent forecasts in the first place. Two key elements of the model - the strategies used and the terrain where the war is fought - are only known ex post, and are revealed during fighting. While any forecast is subject to certain assumptions beforehand, in the case of our model, we must assume what strategies and locations the adversaries will choose during the war if we are to select from various predictions. These choices have a profound impact on the nature of the war that follows. With strategy, we could potentially identify the planned strategies to be used by the militaries in question, and in most cases we would be right. U.S. military doctrine is now generally to engage in maneuver warfare where physically possible, while most militaries only have the capability to engage in attrition-style warfare, so in many cases we could make good estimates of strategy. Also, in some cases the terrain on which a war would be fought is quite clear. Any possible war between the United States and North Korea, or between India and Pakistan, would be fought on much more mountainous, and denser, terrain than is present in Iraq. Hostile terrain may curtail strategy options such as maneuver warfare as envisioned in official U.S. Army doctrine. ${ }^{10}$ In other cases, the choices would not be so clear, as in the case of a state that began with a plan for maneuver but then changes strategy to fight emplaced enemy units, or in the case of a series of possible battle locations over varied terrain. ${ }^{11}$ We do not believe, though, that these contingent forecasts are notably different in type from the best- and worse-case scenarios provided by military planners now. Such scenarios are themselves contingent on a number of different variables, including the strategy choices of the other side.

In sum, our model gave us estimates closer to the reality than would simply a prediction based on the historical mean or median war duration. Moreover, the model's estimates were historically informed, using data on the majority of wars since 1816 (all wars to 1992, subject to data availability). Finally, and most simply,

\footnotetext{
after 27 or 43 days (depending on definition). But if the end of the war is defined as "pacification," cessation of violence, or a more widespread acceptance of the legitimate authority of a new leadership, then the war has not yet ended, however. In an extension to our original research report - which was focused on the initial conventional ground war-we make a prediction about the war's duration after its transition to a guerrilla/insurgent war.

${ }^{10}$ Field Manual No. FM 3-0, Headquarters, Department of the Army, Washington, DC, June 14, 2001 describes official U.S. army doctrine, which focuses on the combination of maneuver and firepower. "As both an element of combat power and a principle of war, maneuver concentrates and disperses combat power to place and keep the enemy at a disadvantage. It achieves results that would otherwise be more costly. Effective maneuver keeps enemies off balance by making them confront new problems and new dangers faster than they can deal with them. Army forces gain and preserve freedom of action, reduce vulnerability, and exploit success through maneuver." Chapter 4, paragraph 43 .

${ }^{11}$ We seek to avoid another possible problem with strategy, namely that it is endogenous with war length. It would be a problem for our analysis if we coded wars as movement simply because one force overruns the other, giving the appearance of rapid movement, when in fact it might have won through the overwhelming application of attrition-style force. We seek to avoid this by looking at how military forces were used and not simply their effect, such as whether the effort was to bypass and cut off major enemy concentrations or defeat them in main battle.
} 
the model provided estimates and the backing behind those estimates, providing a base point for further discussion. In the absence of any other predictions, we believe that making the prediction was in fact quite useful.

\section{Part 3: Additional Forecasts}

In 2004, we used the model to predict the hypothetical duration of a guerrilla war in Iraq, a war between Syria and the United States, and a war between North Korea and the United States (along with South Korea). We did not initially analyze these situations. These predictions were made well after April 2003, but can further inform us about policy relevant to war duration. The model's predictions about these situations are revealing, and we present these forecasts here for the first time.

\section{U.S.-Iraq: Insurgency and Guerrilla Warfare}

While major conventional warfare between organized U.S. and Iraqi forces ended very quickly in 2003, significant attacks against United States and international military and civilian operations have continued in the two years since. The number of U.S. fatalities after the main ground war ended has surpassed-by several times - the number of U.S. fatalities incurred during the main offensive. Clearly, there is a strong insurgency continuing to attack U.S. and forces of the new Iraqi regime. In terms of our model, the attacks match the description of a "punishment" strategy whose intention is to coerce the defender into changing its policy aims; in this case, the insurgents hope to coerce the U.S. to leave Iraq rather than staying to support the new Iraqi government. As discussed in Stam (1996) and Bennett and Stam (1996), punishment strategies attempt to inflict such high costs on an opponent that they accept outcomes short of their prewar aims even though their military forces may not actually be defeated in battle. Such punishment strategies are not necessarily counter-force strategies, as costs may be inflicted through attacks on nonmilitary targets (civilian contractors, police, political leaders). The punisher is simply counting on being able to break the resolve of the enemy. Guerrilla warfare is a type of offensive punishment strategy. In Iraq, ongoing attacks on U.S. and Iraqi forces appear unable to defeat well-prepared forces in head-to-head battle, but instead are acting to increase the political costs to the United States of remaining in Iraq, and the costs to Iraqis of supporting the new regime.

Initially, there were significant questions as to whether continuing resistance to the U.S. and new Iraqi authorities was being centrally coordinated, and whether resistance was orchestrated by Iraqis or by "foreign fighters" entering Iraq. If the ongoing fighting were in fact primarily because of outside forces, then it is unclear how easily we could apply our model, as we would need to include estimates of the strength of such forces in a new balance of forces, the regime types of their backers, and other model variables. On the other hand, if the continuing fighting is part of a coordinated strategy where most of the forces are Iraqi, using a strategy designed to punish the United States for its occupation and defeat the U.S. by forcing a withdrawal, then our model could apply. The latter of these circumstances now seems to be the case, with some "former regime elements" joining with others in resisting the new government. ${ }^{12}$

We make a prediction from our model by continuing to use pre-war Iraqi capability figures and assuming that the only change is on the Iraqi side (now Iraqi insurgents) which shifts to a punishment strategy. While the number of actual

\footnotetext{
${ }^{12}$ For instance, the Brookings Institution "Iraq Index" estimates as of June 2005 that there are perhaps 1,000 foreign fighters out of an estimated insurgency strength of 15-20,000 (O'Hanlon and Albuquerque 2005).
} 
fighters is clearly less now than the original Iraqi army, Iraqi insurgents appear to have collected Iraqi military equipment and are drawing fighters from former Iraqi soldiers, among others. We assume an attrition strategy on the part of the United States: U.S. military forces have been seeking to destroy insurgent forces, and have undertaken offensive actions in insurgent strongholds such as Fallujah and, earlier, against opposing forces such as those under Moktada Al-Sadr. The U.S. has been unable to rely on maneuver to disrupt insurgent forces (there are no clear supply lines or command structures), and has sought to do much more than simply inflict minor or political punishment on the forces opposing it. In terms of terrain, the United States has continued to fight on a variety of terrain, both within and outside major cities, and so we assume mixed terrain in this scenario. The model then yields the following prediction:

Scenario:

U.S. attrition

Iraq punishment

Mixed terrain

Expected duration (months):

83.0

As expected from what we know of the earlier model, the expected duration of a U.S.-Iraq war given an Iraqi guerrilla/punishment strategy jumps significantly, to almost seven years. Is this a reasonable prediction? In 2003 and even during the U.S. 2004 presidential campaign, this might have appeared to be a pessimistic and unjustifiable prediction. As of 2005, though, it is clearly not beyond the realm of possibility that U.S. forces will need to be in place for an extended period of time to help stabilize the new regime. The U.S. timeline for the withdrawal of military forces has been extended several times, and reports continue to show that few Iraqi forces are ready to assume control of major geographic areas or to fight the insurgency on their own. In June 2005, U.S. Secretary of Defense Donald Rumsfeld acknowledged that a long stay might be required, as "insurgencies tend to go on 5, 6, 8, 10, 12 years" (quoted in Knowlton 2005). Of course, it is possible that the United States will withdraw from Iraq after putting into place local authority, even if it is imperfect or the prospects for stability are weak. At intervals, statements from the Pentagon and Bush administration suggest that military forces could begin to return home "soon." But given the current unstable situation, if the U.S. did not simply pull out, could U.S. forces continue to come under significant attack for seven years? Quite possibly-hence the reasonableness of the prediction.

\section{U.S.-Syria}

At the end of the Iraq-U.S. war, Syrian leaders appeared to develop a serious concern that the U.S. might continue its war against Iraq into Syria. Substantive issues of concern for the U.S. and Syrian leaders included the discovery of military equipment in Iraq apparently transshipped via Syria, a stated lack of Syrian cooperation in closing the Syrian/Iraqi border to fleeing members of the Iraqi regime, and reports of U.S. military incursions into Syrian territory. Strong warnings were issued by the U.S. to Syrian leaders, followed by public statements by Syrian authorities expressing clear concern about a U.S. attack, and ultimately reassurances (whether truthful or not) by the united States that it had no intention of invading Syria. Why was Syria so concerned about this? What did it see in a possible Syria-U.S. war that would lead to its reactions? We present contingent predictions of the length of a hypothetical war in 2003 between the U.S. and Syria below. As with the case of Iraq, we make four predictions, varying terrain type 
(depending on whether the U.S. could remain in relatively open terrain, or instead would have to fight in rougher terrains of hills and cities) and U.S. strategy. We assumed that the Syrian army would be forced to use an attrition strategy given its available forces and training. ${ }^{13}$

\begin{tabular}{lllll}
\hline Scenario: & 1. & 2. & 3. & 4. \\
& U.S. maneuver & U.S. maneuver & U.S. attrition & U.S. attrition \\
& Syria attrition & Syria attrition & Syria attrition & Syria attrition \\
& Open terrain & Mixed terrain & Open terrain & Mixed terrain \\
Expected duration (months): & 0.81 & 2.45 & 9.83 & 11.4 \\
\hline
\end{tabular}

The most important observation to make about these predictions is that while the precise values vary slightly, the forecast length of a U.S.-Syrian war is remarkably close to the forecast length of the U.S.-Iraq war. This prediction emerges from the underlying data, as the characteristics of Syria and Iraq (such as military size and regime type), and the likely war that would be fought (in terms of terrain and strategies), are quite similar. While it appears unlikely that the U.S. ever intended to invade Syria, a reasonable assessment from the Syrian side could be that if war occurred, it would be very similar to the just-concluded war between the U.S. and Iraq, with rapid U.S. advance and defeat of Syrian forces. At the time (preinsurgency, and with most expectations being that U.S. would secure Iraq and easily establish a new leadership), this would appear to be an inexpensive U.S. victory. Given that U.S. victory would be almost certain absent the Syrian regime being able to organize a large-scale insurgency, it would be easy to speculate that the U.S. might choose to continue its campaign of regime change. Nervousness on the part of the Syrians seems quite reasonable given this prediction.

\section{U.S.-North Korea}

A possible conflict between the U.S. and North Korea was a somewhat more muted topic of conversation in the lead-up to the U.S.-Iraq war, with critics of the Bush administration noting that North Korea appeared to be a more immediate and dangerous threat than Iraq, and suggesting that the administration had picked the wrong target. North Korea was in open violation of international agreements, and was pursuing (and perhaps possessed) nuclear weapons, not "just" chemical ones. Some ad hominem attacks even suggested that George Bush (junior) had a chip on his shoulder and was ignoring the larger threat of North Korea in order to finish the job that former U.S. President George Bush (senior) started in 1991. There were likely to be several reasons that North Korea was not made a target of direct military attack, of course: North Korea was much more introverted than Iraq, and was perhaps not seen as great a threat to its neighbors as "expansionist" Iraq; other options for diplomacy existed with North Korea, increasingly involving Chinese pressure; and there was perhaps less of an excuse domestically for war with North Korea given that the U.S. public had had over ten years of nearly continuous priming for conflict with Iraq. The simplest reason for choosing Iraq over North Korea, though, is simply that North Korea was a much tougher target. Even setting aside the possibility of nuclear weapons use (and the suggestion that nuclear deterrence worked to keep the U.S. out), the difficult terrain and size of a much larger

\footnotetext{
${ }^{13}$ The full set of values used for this prediction are: strategy = OMDA or OADA (contingent strategy); territory $=0$ (open) or 0.45 (mixed); balance of forces $=0.905$; total military personnel $=1.69$; total population $=.295 ;$ population ratio $=17.3 ;$ quality ratio $=40.5 ;$ surprise $=0 ;$ salience $=1$; repression $=-6$; democracy $=10 ;$ previous disputes $=0$; and number of states $=2$.
} 
North Korean army combine to make a longer war the likely outcome. How much longer? Predictions emerging from our model give us one possible answer.

Contingent predictions of the length of a war in 2003 between the U.S. and North Korea are given below. In this case, given the terrain in North Korea, we do not make a contingent prediction based on terrain type, but instead assume that the war would have to be fought largely on rugged terrain. We assumed that the North Korean army would use an attrition strategy, most likely on defense. We make contingent predictions based on whether the United States (and South Korea) would be able to adopt a maneuver strategy to disrupt the North Korean military, or would be forced to fight unit by unit (attrition). ${ }^{14}$

\begin{tabular}{lll}
\hline Scenario: & 1. & 2. \\
& U.S./S. Korea maneuver & U.S./S. Korea attrition \\
& N. Korea attrition & N. Korea attrition \\
& Rugged terrain & Rugged terrain \\
Expected duration (months): & 10.1 & 24.6 \\
\hline
\end{tabular}

The estimated contingent durations of a war with North Korea are much longer than the closest comparable durations vs. Iraq or Syria. Even if the United States and South Korean militaries were to stick to a maneuver strategy, the rugged terrain and size of North Korean military combine to push the duration estimate to 10 months vs. 2.5 in Iraq. If the United States and South Korean militaries must resort to fighting unit by unit to defeat the North Korean military, our estimate more than doubles, to two years vs. 12.3 months in Iraq. Now, while we might discount the possibility that the U.S. would actually fight a two-year-long war (either that it would have to, or that it would be willing to), it is clear that a war against North Korea would take much longer than the war against Iraq. ${ }^{15}$ This then gives us a simple explanation for why the U.S. engaged Iraq rather than North Korea-it was a purely rational calculation. It would be very hard to win a war against North Korea as quickly as against Iraq. This likelihood makes other options-like negotiation-relatively more attractive in the North Korean case. We need not rely on noncharitable explanations (like completing what Bush senior did not) to explain why the United States went to war against Iraq rather than North Korea.

\section{Conclusions}

Although not intended as a forecasting model, and particularly not one intended to apply to a future war where new technologies and tactics were adopted by a much larger state against a smaller one, the statistical model from Bennett and Stam (1996) can clearly be used to make interesting and useful predictions of war duration in current scenarios. Contingent predictions from the model can be used both during an ongoing conflict and to look at other hypothetical conflicts in order to shed light on decision making and the politics of war. If the model had been designed from the ground up as a forecasting model, we might have made somewhat different extensions to it than if we were to maintain its initial focus as a theoretical model. For instance, we would probably pay more attention to time trends and heteroscedasticity over military asymmetry, as we would be explicitly designing to make extrapolated, out-of-sample predictions. Along the same lines, we might devote more effort to examining the effects of particular technologies on the battlefield. This may be particularly important

\footnotetext{
${ }^{14}$ The full set of values used for this prediction are: strategy = OMDA or OADA (contingent strategy); territory $=0.80$; balance of forces $=0.855$; total military personnel $=3.13$; total population $=0.349$; population ratio $=13.5$; quality ratio $=108$; surprise $=0$; salience $=1$; repression $=-5.86$; democracy $=9.72$; previous disputes $=3$; and number of states $=3$.

${ }^{15}$ The use of a punishment strategy by North Korea similarly yields a longer prediction than the punishment strategy scenario in Iraq, namely 117 months.
} 
for future policy making because the American army's performance in winning the initial conventional war in Iraq seemed to some to signal that a revolution in military affairs had taken place. U.S. Secretary of Defense Donald Rumsfeld, Deputy Secretary of Defense Paul Wolfowitz, and other influential figures often labeled as neo-conservatives argued that military campaigns based on the sudden and overwhelming use of technologically advanced weaponry would end prolonged conflicts. This belief has served as a critical support behind the recently declared U.S. policy of pre-emptive war. Military analysts frequently make such predictions about trends in future warfare, but predictions based on one war should be coupled with our longerterm historical data to avoid the problem of making too much of one case (and hence simply refighting the last war, or learning the wrong lesson from one war).

Finally, we might seek to design a model that allows us to use more dynamic information than our initial study did (which used data primarily collected annually from the Correlates of War and other such major data collections). If we had data on the evolution of force balances, tactics, battles, and political decisions measured at a lower level of temporal aggregation (weekly or monthly, for instance), we could better track evolving conflicts. An analogy here would be that our current relatively static model works like predicting the outcome of a chess match by using ex ante measurements of the characteristics of the match, such as the players' relative world chess federation rankings or how tired they are, or details of the setting of the contest (lighting, chairs, audience) that might favor one side or the other. A more dynamic assessment would update forecasts of the likely conflict outcome as the players adopt different strategies and react to the opponent's moves. Knowing the positions of the players' pieces at mid-game along with initial player and playing field characteristics help us to predict correctly the outcome or duration of a chess match. Both types of information - initial and static, and continuous and dynamic - should be helpful in estimating the outcome or duration of games, and interstate war. Adding such information remains for future work.

\section{Appendix A: Technical Details}

1. Hazard model coefficients (revised model: Bennett and Stam 1996 data, plus 1990, 1991 Iraq, Kuwait, U.S. wars)

\begin{tabular}{|c|c|c|c|c|}
\hline Variable & Coefficient & Standard error & t-ratio & Probability \\
\hline Strategy: OADM & 2.287 & 0.539 & 4.24 & 0 \\
\hline Strategy: OADA & 2.495 & 0.489 & 5.1 & 0 \\
\hline Strategy: OADP & 4.857 & 1.084 & 4.48 & 0 \\
\hline Strategy: OPDA & 8.495 & 2.063 & 4.12 & 0 \\
\hline Terrain & 2.323 & 2.571 & 0.9 & 0.366 \\
\hline Terrain $\times$ strategy & -1.002 & 0.669 & -1.5 & 0.134 \\
\hline Balance of forces & -4.470 & 1.226 & -3.64 & 0 \\
\hline Total military personnel & 0.123 & 0.039 & 3.19 & 0.001 \\
\hline Total population & 0.825 & 0.552 & 1.5 & 0.135 \\
\hline Population ratio & 0.008 & 0.012 & 0.65 & 0.513 \\
\hline Quality ratio & 0.007 & 0.006 & 1.05 & 0.292 \\
\hline Surprise & -0.176 & 0.559 & -0.31 & 0.753 \\
\hline Salience & 0.387 & 0.207 & 1.87 & 0.061 \\
\hline Repression & -0.223 & 0.113 & -1.97 & 0.049 \\
\hline Democracy & -0.104 & 0.055 & -1.9 & 0.058 \\
\hline Previous disputes & -0.006 & 0.057 & -0.11 & 0.911 \\
\hline Number of states & -0.193 & 0.092 & -2.09 & 0.037 \\
\hline Constant & 2.641 & 1.233 & 2.14 & 0.032 \\
\hline$p$ (duration param.) & 0.923 & 0.083 & & \\
\hline
\end{tabular}

$n=80$ wars, 171 data points (war-years). 
2. Estimation procedure

Analysis was conducted using the statistical program Stata v7.0 (Statacorp, http:// www.stata.com), using the streg procedure with a Weibull specification, robust standard errors, and the "nohr time" options for purposes of coefficient presentation. Estimation of the initial model presented in Bennett and Stam (1996) was conducted using the LIMDEP software.

3. Expected duration

Expected duration is estimated following the corrected version of Greene's (1993) Econometric Analysis as noted in Bennett and Stam (1996), namely, $E(t \mid X)=$ $\exp \left(\beta^{\prime} x\right) \times \Gamma(1 / \rho+1)$.

\section{References}

Bennett, D. Sсотт. (1999) Parametric Models, Duration Dependence, and Time-Varying Data Revisited. American Journal of Political Science 43:256-270.

Bennett, D. Scott, and Allan Stam. (1996) The Duration of Interstate Wars, 1816-1985. American Political Science Review 90:239-257.

Box-Steffensmeier, Janet M., And Bradford S. Jones. (1997) Time is of the Essence: Event History Models in Political Science. American Journal of Political Science 41:1414-1461.

Box-Steffensmeier, Janet M., and Bradford S. Jones. (2004) Event History Modeling. New York: Cambridge.

Cioffi-Revilla, Claudio. (1991) On the Likely Magnitude, Extent, and Duration of an Iraq-UN War. Journal of Conflict Resolution 35:387-411.

Goemans, Hein E. (2000) War E Punishment; The Causes of War Termination and the First World War. Princeton: Princeton University Press.

Greene, William H. (1993) Econometric Analysis. $2^{\text {nd }}$ edition. New York: Macmillan Publishing Company.

Jaggers, Keith, and Ted Robert Gurr. (1995) Tracking Democracy's Third Wave with the Polity III Data. Journal of Peace Research 32:469-482.

Knowlton, Brian. (2005) Rumsfeld Speaks Cautiously on Strength of Insurgency, New York Times, June 26, 2005.

Lancaster, Tony. (1990) The Econometric Analysis of Transition Data. Cambridge: Cambridge University Press.

NEW YORK TIMES. (2003) A Week at War: Unexpected Resistance and a Change in Plans, New York Times, March 26, 2003.

O’Hanlon, Michael E., and Adriana Lins de Albuquerque. (2005) Iraq Index, June 30, 2005. Available at http://www.brookings.edu/iraqindex.

Roberts, Les, Riyadh Lafta, Richard Garfield, Jamal Khudhairi, and Gilbert Burnham. (2004) Mortality Before and After the 2003 Invasion of Iraq: Cluster Sample Survey. Lancet 364(9448): 1857-1864.

Slantchev, Branislav L. (2004) How Initiators End Their Wars: The Duration of Warfare and the Terms of Peace. American Journal of Political Science 48:813-829.

Small, Melvin, and J.David Singer. (1982) Resort to Arms: International and Civil Wars, 1816-1980. Beverly Hills: Sage Publications.

Stam, Allan C. III (1996) Win, Lose or Draw: Domestic Politics and the Crucible of War. Ann Arbor: University of Michigan Press. 
